\title{
Advanced Adaptive Particle Swarm Optimization based SVC Controller for Power System Stability
}

\author{
Poonam Singhal \\ YMCA Univ. of Science and Technology/Electrical Engg, Faridabad, India \\ Email: ymcapoonamsinghal@gmail.com
}

\author{
S. K. Agarwal, Narendra Kumar \\ YMCA Univ. of Science and Technology, DTU /Electronics Engg, Electrical Engg, Faridabad, Delhi, India \\ Email: \{sa_3264@yahoo.co.in, dnk_1963@yahoo.com\}
}

\begin{abstract}
The interconnected systems is continually increasing in size and extending over whole geographical regions, it is becoming increasingly more difficult to maintain synchronism between various parts of the power system. This paper work presents an advanced adaptive Particle swarm optimization technique to optimize the SVC controller parameters for enhancement of the steady state stability \& overcoming the premature convergence \& stagnation problems as in basic PSO algorithm \& Particle swarm optimization with shrinkage factor $\&$ inertia weight approach (PSO-SFIWA). In this paper SMIB system along with PID damped SVC controller is considered for study. The generator speed deviation is used as an auxiliary signal to SVC, to generate the desired damping. This controller improves the dynamic performance of power system by reducing the steady-state error. The controller parameters are optimized using basic PSO, PSO-SFIWA \& Advanced Adaptive PSO. Computational results show that Advanced Adaptive based SVC controller is able to find better quality solution as compare to conventional PSO \& PSO-SFIWA Techniques.
\end{abstract}

Index Terms - Small Signal Stability SMIB (single machine on infinite bus bar), SVC (Static Var Compensator), Particle Swarm Optimization (PSO), PSO with Shrinkage Factor \& Inertia Weight Approach (PSO-SFIWA), PSO with Time Varying Acceleration Coefficients (PSO-TVAC)

\section{INTRODUCTION}

Small signal stability analysis is a study about the dynamic stability limits of synchronous machines resulted from poorly damped rotor oscillations under small perturbations or disturbances [1] [2]. These disturbances continuously occur on the power system because of small variation in load and generation. The perturbations are considered sufficiently small, in order to make system equations linearized. The dynamic performance of the machine can be improved by suitable control methods. The instability condition may result in two forms:

a) Steady increase in rotor angle due to lack of sufficient synchronizing torque.

b) Rotor oscillations of increasing amplitude due to the lack of sufficient damping torque [1].

In today's practical power system, small signal stability is a problem of insufficient damping of oscillations. Today, the fast acting static excitation systems are available for the modern power system and they have a large impact on the small signal stability of power systems. At the range of $0.1 \mathrm{~Hz}$ to $2.5 \mathrm{~Hz}$ in electromechanical oscillation frequencies of the machine, these excitation systems introduce negative damping [2], so that they make the system unstable under local and inter area modes of oscillations. And when, we have a weak system with the weak tie lines, a small disturbance can also make the system unstable. So the dynamic behavior of the synchronous machine under small disturbance is studied to determine small signal stability $\&$ there is a need of positive damping in order that generators remain in synchronism under small disturbances. Recent advances in power electronics lead to the introduction of Flexible Alternating Current Transmission (FACT) devices. These devices are capable of improving the power system stability [1]. Tuning of control parameters of FACT devices is complex exercise. Various conventional techniques like gradient descent, Ziegler Nichols, mathematical programming \& eigen value analysis are employed pertaining to their design problems. These conventional methods are time consuming, having slow convergence rate and during the search operation they might trap in local minima, due to which optimal solution may not be achieved [6]. Researchers study reveals that AI based FACTS devices are more efficient for power system stability than conventional power system stabilizers. Various computational intelligence techniques have been widely used in solving power system stability problems. Amongst the popular techniques are Evolutionary Programming (EP), Particle Swarm Optimization (PSO), Genetic Algorithm, Artificial Immune System (AIS), Bacterial Foraging Optimization and Hybrid BF-PSO. These algorithms are heuristic population-based search methods that used both random variation and selection. In this paper Advanced Adaptive PSO tuned PID damped SVC (Static Var Compensator) controller is proposed .The simulation results justify the optimization efficacy of the proposed Advanced Adaptive PSO over basic PSO \& PSO-SFIWA .

The present paper is laid out as follows:

Section I - Introduction, section II describes about the Static Var Compensator (SVC). Section III gives the 
review of work done by different researchers in various fields using a number of evolutionary techniques. Section IV gives a brief description of Particle Swarm Optimization Technique. Section V describes about PSOSHRINKAGE Factor with time varying Inertia weight approach (PSO-TVIWA) for global search of Controller parameters. Section VI proposes the implementation of Advanced Adaptive (PSO-TVAC) Technique for optimizing the parameters of SVC Controller for better global search. Section VII describes the formulation of an objective function to be minimized. Section VIII describes the mathematical modeling of SVC Controller. Study system has been described in section IX. Section X gives the description of proposed PID-damped SVC Controller connected to an SMIB system. Simulation results have been shown in section XI and finally the conclusion in section XII.

\section{Static VAR COMPENSATOR (SVC) DeSCRIPTION}

SVC's are first generation FACTS controllers which are expected to revolutionize power transmission in future. SVC provides an excellent source of rapidly controllable reactive shunt compensation for dynamic voltage control through its utilization of high-speed thyristor switching controlled devices. SVC is typically made up of coupling transformer, thyristor valves, reactors, capacitance (often tuned for harmonic filtering)[4].They are used to control the voltage profile under load variations, increase power transfer capability and improve system stability[5]. They can be used for damping power system oscillations incorporating some auxiliary signals.

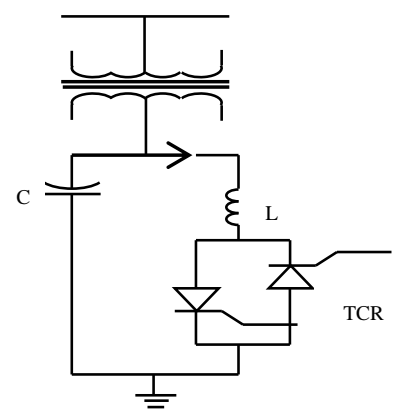

Fig. 1. Configuration of SVC Controller

\section{ABOUT PASt STUdIES}

A number of evolutionary techniques like BFO, GA, PSO, hybrid BF-PSO, BF with PSO biased evolution Ant Colony, water droplet optimization technique \& many more has been proposed by many researchers [6-11]. Wang has applied advanced no velocity PSO for grid scheduling [12]. Attractive and Repulsive Particle Swarm Optimization has been used for orienteering problem in paper [13]. Rehab [14] has applied Genetically Improved PSO Algorithm for Efficient Data Clustering. Paper [7] has suggested centroid based PSO technique. Paper [15] has applied Hybrid PSO which is based on the fusion of the PSO, Clonal Selection Algorithm, and Mind
Evolutionary Computation. An Ant Colony Optimization based clustering algorithm was introduced by Shelokar [10]. Jin-Zhu $\mathrm{Hu}$ has explained the algorithm of PSO with dynamic inertia weight in paper [18].Complex ELD problem has been solved by BF with PSO biased evaluation in paper reference [17].

\section{OVERVIEW OF PARTICLE SWARM OPTIMIZATION}

PSO was introduced by Eberhart and kennedy in1995 [20]. It is a heuristic \& stochastic based optimization technique. PSO can be used on optimization problem that are partially irregular, noisy, change over time, etc. It is developed from swarm intelligence and is based on the research of bird and fish flock movement behavior. The particle swarm optimization consists of swarm of particles which are initialized with a population of random candidate solution in the multidimensional search space. During their flying movement they follow the trajectory according to their own best flying experience (pbest) \& best flying experience of the group (gbest). During this process, each particle modify its position and velocity according to shared information to follow the best trajectory leads to optimum solution \& this technique is simple \& very few parameters need to be determined. The choice of PSO parameters can have a large impact on optimization performance. Selecting PSO parameters that yield good performance has therefore been the subject of much research. The PSO algorithm consists of just three steps, which are repeated until some stopping condition is met.

1. Initialize the number of particles, initial particle position \& velocity

$$
v_{i d}^{k}=v_{\min }+\left(v_{\max }-v_{\min }\right) * \operatorname{rand}()
$$

Where,

$$
\begin{gathered}
v_{\text {max }}=0.1 *\left(m_{\max }-m_{\min }\right) \\
v_{\text {min }}=-0.1 *\left(m_{\text {max }}-m_{\min }\right) \text {, while } m_{\max } \text { and } m_{\text {min }} \text { are }
\end{gathered}
$$
maximum and minimum limits for the d-dimension search space.

$$
x_{i d}^{k}=m_{\min }+\left(m_{\max }-m_{\min }\right) * \operatorname{rand}()
$$

Thereafter evaluate the fitness of each particle and define pbest $\&$ gbest.

2. Update velocity and position of each particle.

$$
\begin{aligned}
v_{i d}^{k+1}=v_{i d}^{k} & +c 1^{*} \operatorname{rand} 1\left(\text { pbest }_{i}^{k}-x_{i d}^{k}\right) \\
& +c 2 * \operatorname{rand} 2\left(\text { gbest }^{k}-x_{i d}^{k}\right) \\
x_{i d}^{k+1}=x_{i d}^{k} & +v_{i d}^{k+1}
\end{aligned}
$$

$c 1$ and $c 2$ represents the acceleration factors, and represents distributed random numbers between $(0,1)$. First part of (1) depicts the previous velocity of the particle, the second part is a positive cognitive component $\&$ third part is a positive social component as described in [25]. 
3. Update individual (pbest) and global best (gbest) fitness and position.

$\mathrm{V}_{\mathrm{id}}{ }^{\mathrm{k}}$ and $\mathrm{x}_{\mathrm{id}}{ }^{\mathrm{k}}$ defines separately the velocity \& position of the particle $\mathrm{i}$ at its $\mathrm{k}$ times iteration and the $\mathrm{d}$ dimension quality of its position:

pbest $_{i d}{ }^{k}$ represents the d-dimension quality of the individual $\mathrm{i}$ at its best optimized position at its $\mathrm{k}$ times.

gbest $_{\mathrm{d}}{ }^{\mathrm{k}}$ represents the d-dimension quality of the swarm at its best optimized position.

\section{About Pso-ShrinKage FACTOR With TIME VARYING INERTIA APPROACH}

The conventional PSO has the disadvantage of premature convergence \& problem of stagnation. This can be overcome by incorporating additional factor called inertia weight factor $w$, concept of which is explained by Shi \& Ebhert [21] in order to achieve the balance between local \& global search during the iteration process of an optimization problem. Inertia weight plays a vital role in controlling the exploitation and exploration capability of algorithm. For enhancement of performance index of conventional PSO algorithm, one can adjust the inertia weight $\mathrm{w}$, the value of which is linearly reduced during the iterations. Typical values of wmax $\&$ wmin are $0.9 \& 0.4$ respectively. Since there is a need of vast random search in multi-dimensional search space initially $\&$ at later stage when problem is converging to best solution, fine tuning is required. Due to dynamic behaviour of $\mathrm{w}$, this technique can be named as PSOTVIWA as described in paper [20].The inertia weight $\mathrm{w}$ is a function of iteration time and mathematically,

$$
w=w_{\max }-\left(\left(w_{\text {maax }}-w_{\min }\right) / \text { iter } \max \right) \text { iter }
$$

This technique had some limitations of not converging towards global minima. In order to converge efficiently and to avoid explosion of the particle swarm, an additional new parameter called shrinkage factor/constriction factor $\mathrm{K}$ has been proposed by clerc et al [23, 24].Mathematical representation of updated particle velocity and position using shrinkage factor is given as follows:

$$
\begin{aligned}
& v_{i d}^{k+1}=S\left(\begin{array}{r}
w^{*} v_{i d}^{k}+c 1^{*} \operatorname{rand} 1\left(\text { pbest }_{i}^{k}-x_{i d}^{k}\right) \\
+c 2 * \operatorname{rand} 2\left(\text { gbest }^{k}-x_{i d}^{k}\right)
\end{array}\right) \\
& x_{i d}^{k+1}=x_{i d}^{k}+v_{i d}^{k+1}
\end{aligned}
$$

$x_{i d}^{k}$ is the previous position of the particle and $v_{i d}^{k+1}$ is the updated particle velocity.

Mathematically, Shrinkage factor has been represented as

$$
S=\frac{2}{\mid 2-\theta-\sqrt{\theta^{2}-4 \theta \mid}}
$$

$$
\theta=c 1+c 2 \text { and } \boldsymbol{\theta}>4
$$

Normally, values of $\mathrm{c} 1$ and $\mathrm{c} 2$ lie between 0.5 to 2.05 for $\mathrm{c} 1=\mathrm{c} 2=2.05$, the computed value of $S=0.73$.
These values can be changed according to the optimization problem.

\section{IMPLEMENTATION OF ADVANCED ADAPTIVE (PSO- TVAC) TECHNIQUE FOR SVC CONTROLLER}

This strategy has the advantage of both fast convergence as well as fine tuning to global minima [26]. Both cognitive part and social part of velocity plays an important role in optimising to global minima. In order to increase the randomness at the initial stage, value of $\mathrm{c} 1$ is made larger than $\mathrm{c} 2$. This allows particle to search the optima in the whole m-dimensional search space. Lower value of $\mathrm{c} 1$ can lead to trapping into local minima due to premature convergence. Whereas, higher value of $\mathrm{c} 2$ than c1 is desired at later stage to enhance the social interaction and hence converges efficiently to global minima. It is mentioned here that this algorithm is used with time varying inertia weight factor. Mathematically updated particle velocity and position is represented as:

$$
\begin{aligned}
& v_{i d}^{k+1}=K\left(\begin{array}{r}
w^{*} v_{i d}^{k}+c 1^{*} \operatorname{rand} 1\left(\text { pbest }_{i}^{k}-x_{i d}^{k}\right) \\
+c 2 * \operatorname{rand} 2\left(\text { gbest }^{k}-x_{i d}^{k}\right)
\end{array}\right) \\
& x_{i d}^{k+1}=x_{i d}^{k}+v_{i d}^{k+1}
\end{aligned}
$$

where modified $\mathrm{c}^{\prime}$ ' and $\mathrm{c} 2$ ' are mathematically represented as [25, 27]:

$$
\begin{gathered}
c 1^{\prime}=\left((c 1 f-c 2 i) * k / K_{\max }\right)+c 1 i, c 1 f \prec c 1 i \\
c 2^{\prime}=\left((c 2 f-c 1 i) * k / K_{\max }\right)+c 2 i, c 2 f \succ c 2 i
\end{gathered}
$$

c1i, c2i, c1f and c2f are initial and final values of $\mathrm{c} 1$ and $\mathrm{c} 2$ respectively. Normally $\mathrm{c} 1$ varies from 2.5 to 0.5 over the full range of search.

\section{FORMULATION OF AN OBJECTIVE FUNCTION}

Objective function formulated is based on the optimization parameters. It is worth mentioning that the PID damped SVC controller is designed to minimize the power system oscillations after a disturbance so as to improve steady state stability. These oscillations are reflected in the deviations in the generator rotor speed $\Delta \mathrm{w}$ and deviation in terminal voltage $\Delta \mathrm{vt}$. In the present study the objective function $\mathrm{J}$ is formulated as the minimization of

$$
J=\int_{0}^{t}\left[t(\Delta \omega(t, x))^{2}+t\left(\Delta v_{t}(t, x)\right)^{2}\right] d t
$$

In the above equations, $\Delta \mathrm{w}(\mathrm{t}, \mathrm{x})$ denotes the rotor speed deviation and $\Delta \mathrm{Vt}(\mathrm{t}, \mathrm{x})$ denotes the variation in terminal voltage for a set of controller parameters $\mathrm{x}$ and (note that, here $\mathrm{x}$ represents the parameters to be optimized i.e $\mathrm{kp}$, ki and $\mathrm{kd}$, the parameters of PID controller) and $t$ is the time range of the simulation. With the variation of the parameters $\mathrm{x}, \Delta \mathrm{w}(\mathrm{t}, \mathrm{x})$ and $\Delta \mathrm{Vt}(\mathrm{t}, \mathrm{x})$ will also be changed. For objective function calculation, the time-domain simulation of the power system model is 
carried out for the simulation period. It is aimed to minimize this objective function in order to improve the system response in terms of the settling time and overshoots.

\section{A. Flow chart of proposed algorithm for controller} design

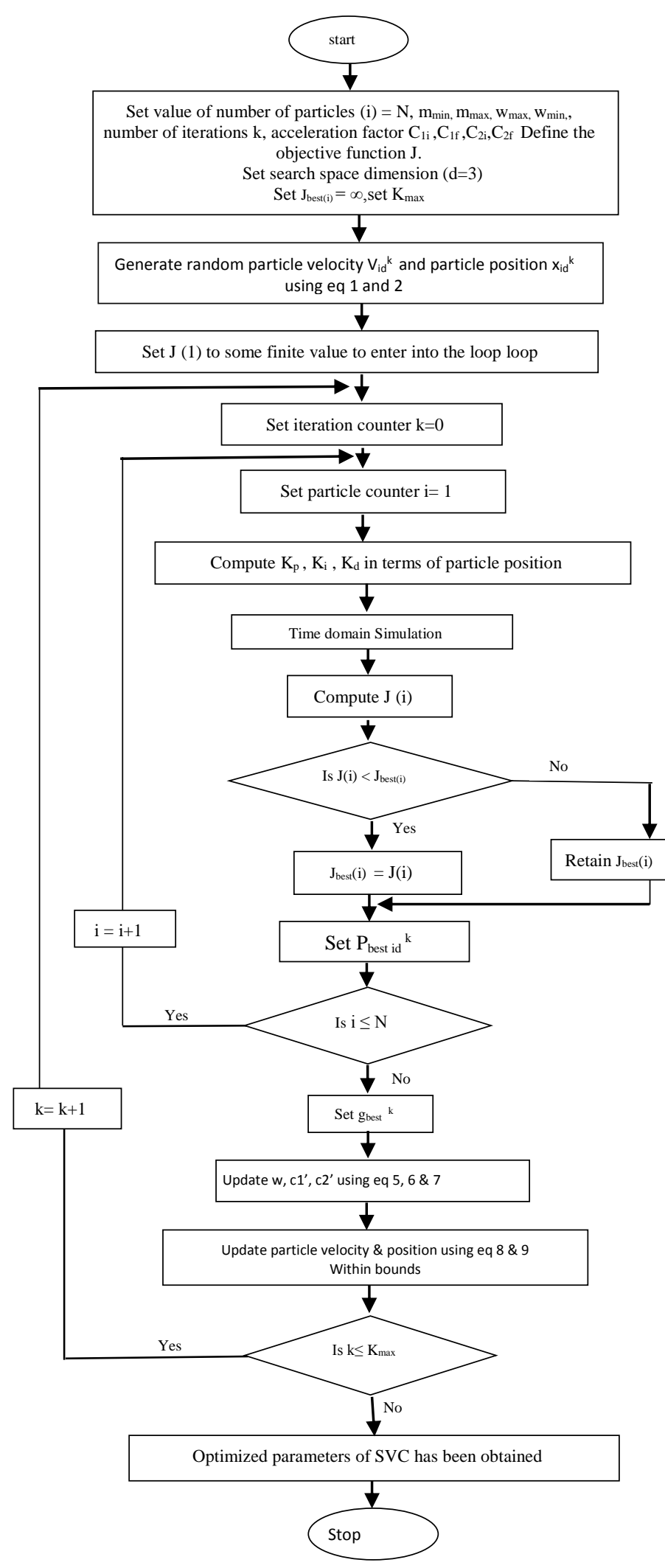

\section{VIII.MATHMETICAL MODELLING}

\section{A. Machine Modeling}

The synchronous generator is represented by 1.1 model, i.e. with field circuit and one equivalent damper winding on $\mathrm{q}$ axis. The machine equations are [2, 3]:

$$
\begin{aligned}
& \frac{d \delta}{d t}=w_{B}\left(S_{m}-S_{m 0}\right) \\
& \frac{d S_{m}}{d t}=\frac{1}{2 H}\left[-D\left(S_{m}-S_{m 0}\right)+T_{m}-T_{e}\right] \\
& \frac{d E_{q}^{\prime}}{d t}=\frac{1}{T_{d o}^{\prime}}\left[-E_{q}^{\prime}+\left(x_{d}-x_{d}^{\prime}\right) i_{d}+E_{f d}\right] \\
& \frac{d E_{d}^{\prime}}{d t}=\frac{1}{T_{q o}^{\prime}}\left[-E_{d}^{\prime}+\left(x_{q}-x_{q}^{\prime}\right) i_{q}\right]
\end{aligned}
$$

The electrical torque is expressed in terms of variables $E_{d}^{\prime}, E_{q}^{\prime}, i_{d}$ and ${ }^{i_{q}}$ as:

$$
T_{e}=E_{d}^{\prime} i_{d}+E_{q}^{\prime} i_{q}+\left(x_{d}^{\prime}-x_{q}^{\prime}\right) i_{d} i_{q}
$$

For a lossless network, the stator algebraic equations and the network equations are expressed as:

$$
\begin{aligned}
& E_{q}^{\prime}+x_{d}^{\prime} i_{d}=v_{q} \\
& E_{d}^{\prime}-x_{q}^{\prime} i_{q}=v_{d} \\
& v_{q}=-x_{e} i_{d}+E_{b} \cos \delta \\
& v_{d}=x_{e} i_{q}-E_{b} \sin \delta
\end{aligned}
$$

Solving the above equations, the variables $i_{d}$ and $\boldsymbol{i}_{q}$ can be obtained as:

$$
\begin{aligned}
& i_{d}=\frac{E_{b} \cos \delta-E_{q}^{\prime}}{x_{e}+x_{d}^{\prime}} \\
& i_{d}=\frac{E_{b} \cos \delta-E_{q}^{\prime}}{x_{e}+x_{d}^{\prime}}
\end{aligned}
$$

The notation of above parameters and variable used are defined in nomenclature [1] [2] [3].

\section{B. Dynamic Modeling of SVC}

The basic SVC model [22] comprises of a measurement module, voltage regulator module \& thyristor sucseptance control module for simulation of SVC control loop stability \& SVC response time. This model is a fundamental frequency model \& suitable for continuous control of SVC. SVC has a reactive/current/susceptance regulator so that SVC can return back to a desired steady state operating point. 


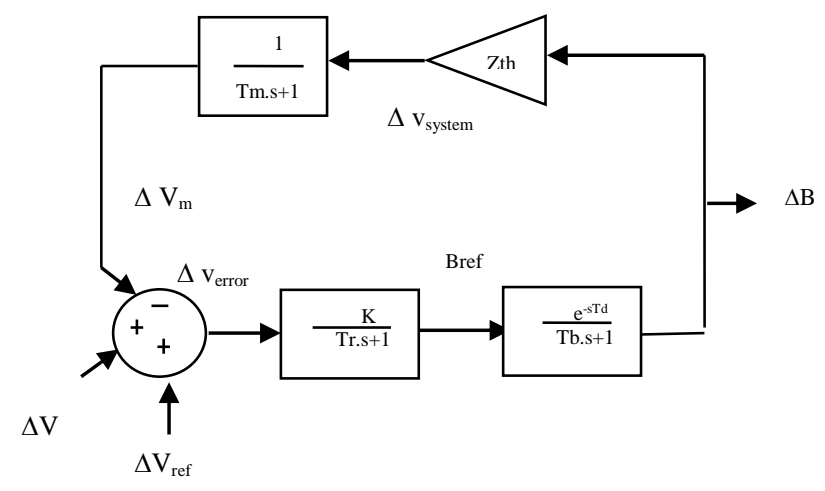

Fig. 2. Model of Static Var Compensator

\section{Measurement Block}

The line voltage \& current measured are converted into quasi-dc control signal $\&$ is proportional to the magnitude of fundamental frequency component of the measured parameter \& the resulting model is a single low frequency filter

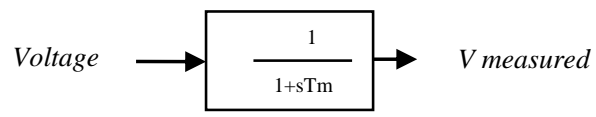

Fig. 3 Measurement module

\section{Voltage Regulator Block}

It is basically a proportional type regulator where $\mathrm{KR}$ is the gain of the regulator $\&$ is reciprocal of the slope setting \& which can be set between $5 \%$ \& $1 \%$ on the SVC base. TR is the regulator time constant which is taken between $20 \& 150 \mathrm{~ms}$. PI controller is being used in some voltage regulator circuit. The generic AVR control block is defined by the transfer function:

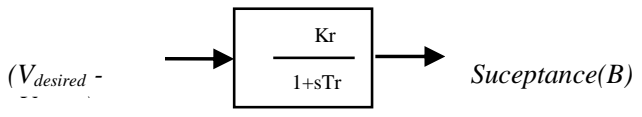

Fig. 4 Voltage regulator block

\section{Thyristor Susceptance Control Module}

The CIGRE model showing Thyristor firing delays is being used in this module where $\mathrm{Td}$ is gating transport delay \& $\mathrm{Tb}$ is effect of Thyristor firing susceptance control (3-6 ms). Bref \& TCR firing angle has nonlinear relationship [22]. The transfer function of thyristor susceptance control is:

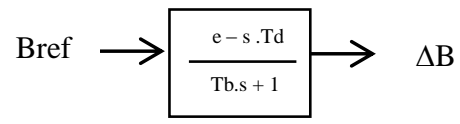

Fig. 5 Thyristor susceptance control block

The Thyristor susceptance block gives the incremental change in the susceptance value when a firing angle delay is given to it. The Zth is the thevenin impedance of SVC controller, which is generally specified as a constant. SVC with additional PID controller is shown in Fig.7 is used, as this introduces an additional damping in the system and damps the rotor mechanical low frequency oscillations quickly. They are placed in the supplementary control signal of SVC.

\section{STUDY SYSTEM}

In this paper, the proposed study system consists of four $555 \mathrm{MVA}, 24 \mathrm{Kv}, 60 \mathrm{~Hz}$ thermal units which are connected to infinite bus system through two parallel transmission lines. The generators are to be modeled as a single equivalent generator represented by the classical model with all the parameters expressed in p.u on 2220 MVA, $24 \mathrm{Kv}$ base. The resistance of the transmission line is neglected in this paper. The linearized mathematical modeling of single machine power system is carried out by linearizing the equations around the operating point [3]. Phillips Heffron model, a linearized model of SMIB system is considered for simulation. SVC is placed at the generator busbar. The machine data is given in the appendix. The network reactances are in p.u on 2220MVA, $24 \mathrm{Kv}$ base. The operating conditions are: $\mathrm{Pg}=0.5$ p.u, $\mathrm{Vt}=1$ p.u and $\mathrm{Eb}=0.995$ p.u. The initial conditions are computed from the operating points [3] and $\mathrm{K} 1$ to $\mathrm{k} 6$ constants of Phillips Heffron model are then derived using the expressions given in the appendix. A small perturbation of 0.1 p.u is then given to examine the steady state stability.

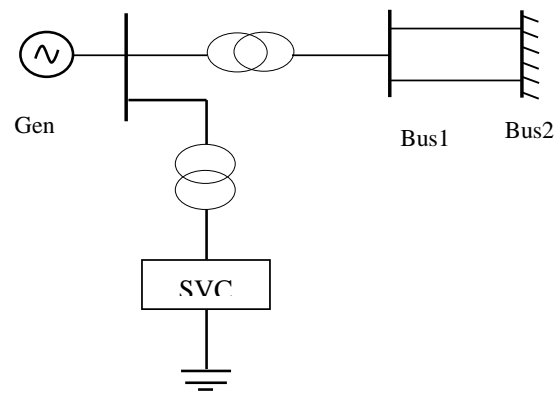

Fig. 6 Single machine infinite bus with SVC

\section{PID DAMPED SVC CONTROLLER}

PID damped SVC controller shown in Fig.7 introduces an additional damping in the system and damps the rotor mechanical low frequency oscillations quickly. They are placed in the supplementary control signal of SVC.

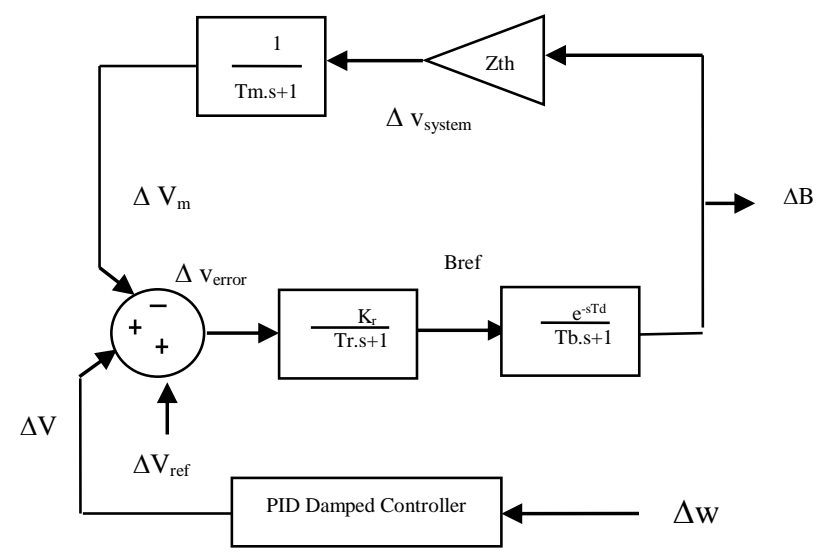

Fig. 7. PID Damped SVC controller

PID damped SVC controller placed at the generator bus is used to improve the dynamic response as well as to 
reduce or eliminate the steady-state error. Unified Phillips Heffron model with PID damped SVC controller is shown in fig. (8). The parameters of PID controller of SVC are optimized firstly by a conventional method and then using these computed parameters as base, the control parameters are computed by PSO-SFIWA and by PSOTVAC Techniques

\section{Simulation}

Simulation is carried out both in MATLAB coding \& MATLAB Simulink by giving small disturbance $\Delta \mathrm{Tm}=$ 0.1 p.u. Four cases have been analyzed:

1. Without SVC controller.

2. With SVC controller.

3. With PSO-SFIWA based PID damped SVC Controller.

4. With PSO-TVAC based PID damped SVC Controller.

The simulation results of the system for all the cases mentioned above with respect to variation in rotor angle, rotor speed deviation \& change in terminal voltage are shown in fig. 9 (a) to 9 (i).

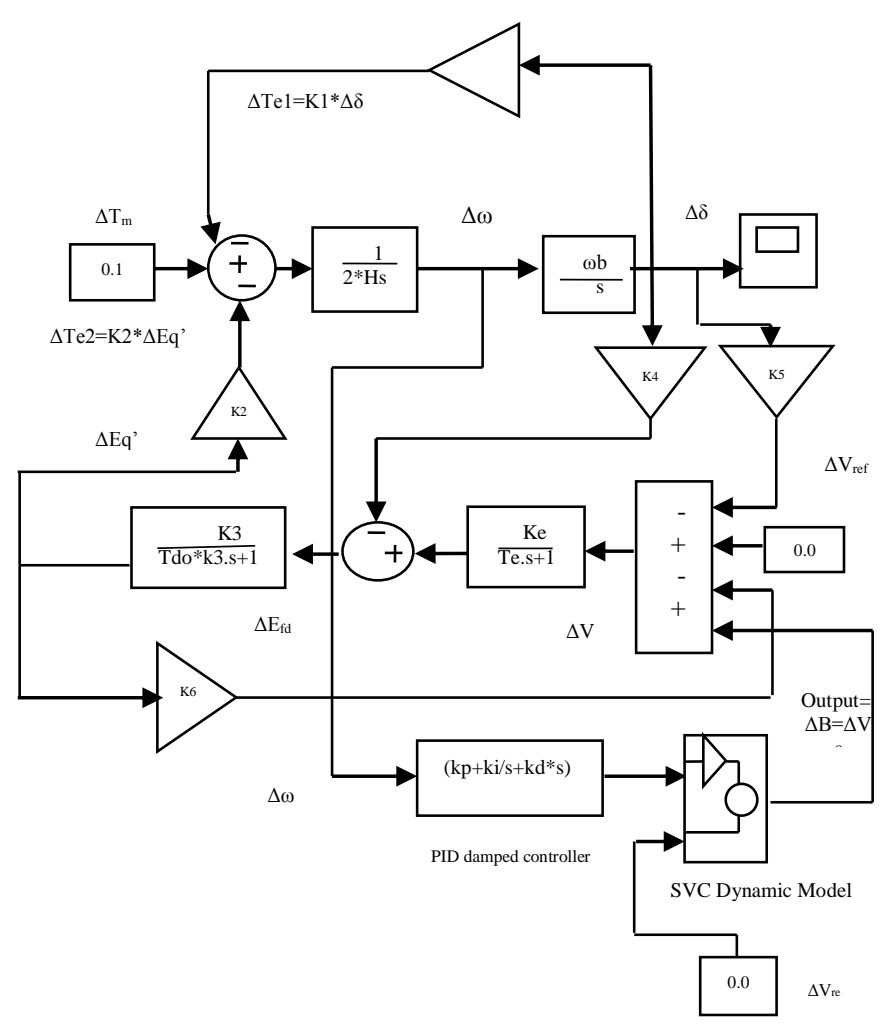

Fig. 8. Phillips Heffron model of SMIB system with PID damped SVC controller

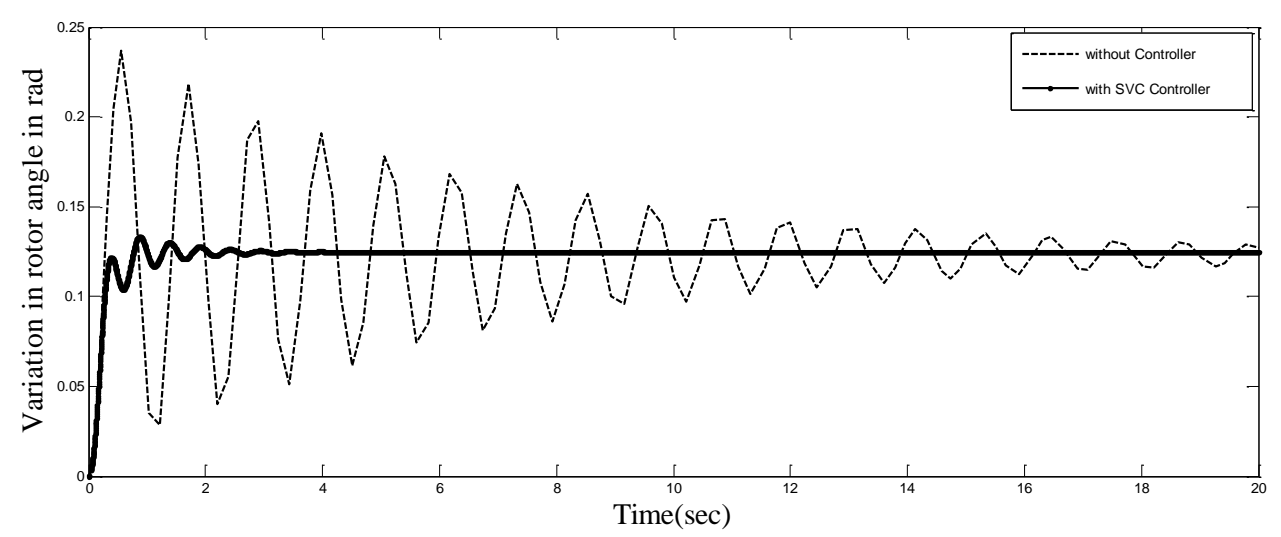

Fig.9a Time Response of Variation in rotor angle

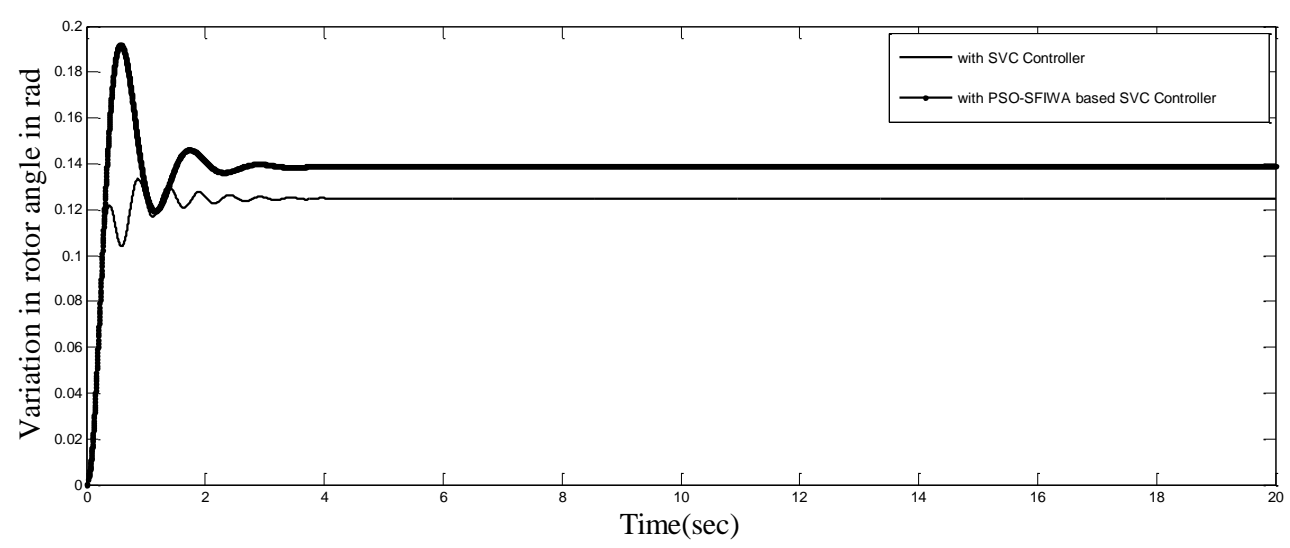

Fig. Fig. 9b Time Response of Variation in rotor angle 


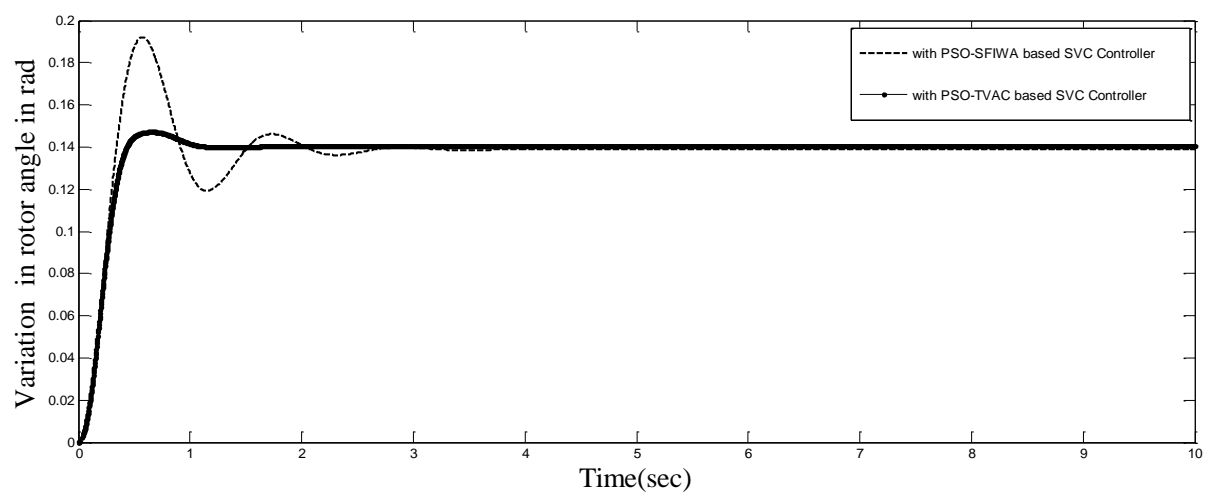

Fig. 9c Time Response of Variation in rotor angle

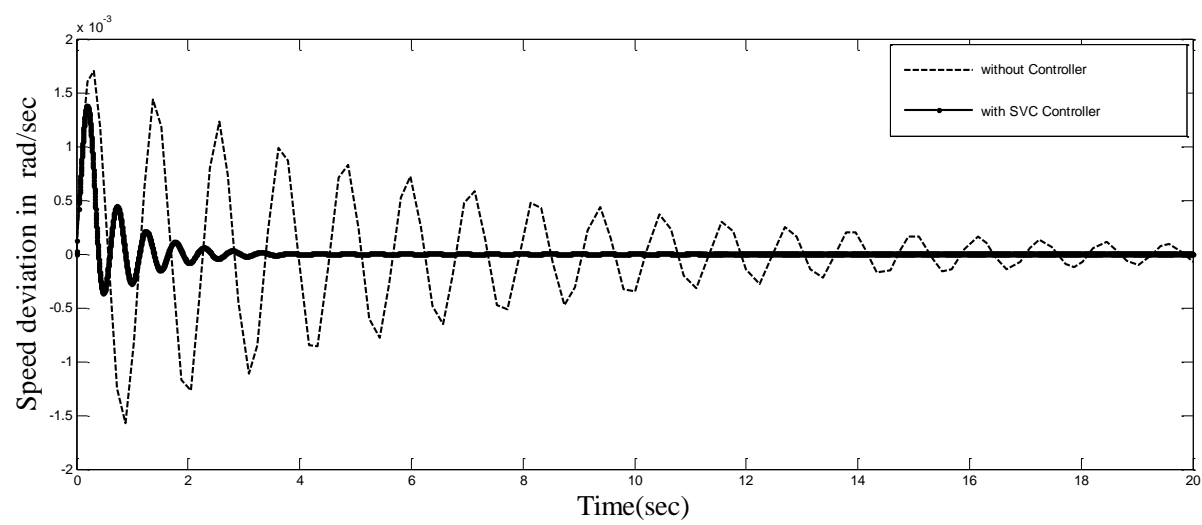

Fig. Fig. 9d Time response of speed deviation

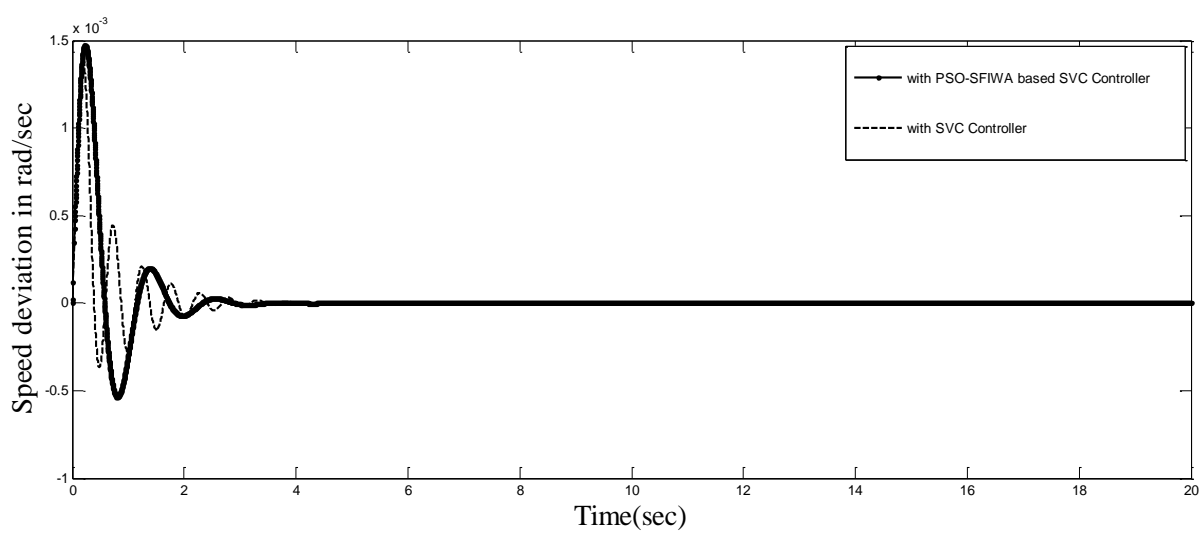

Fig. 9e Time response of Speed deviation

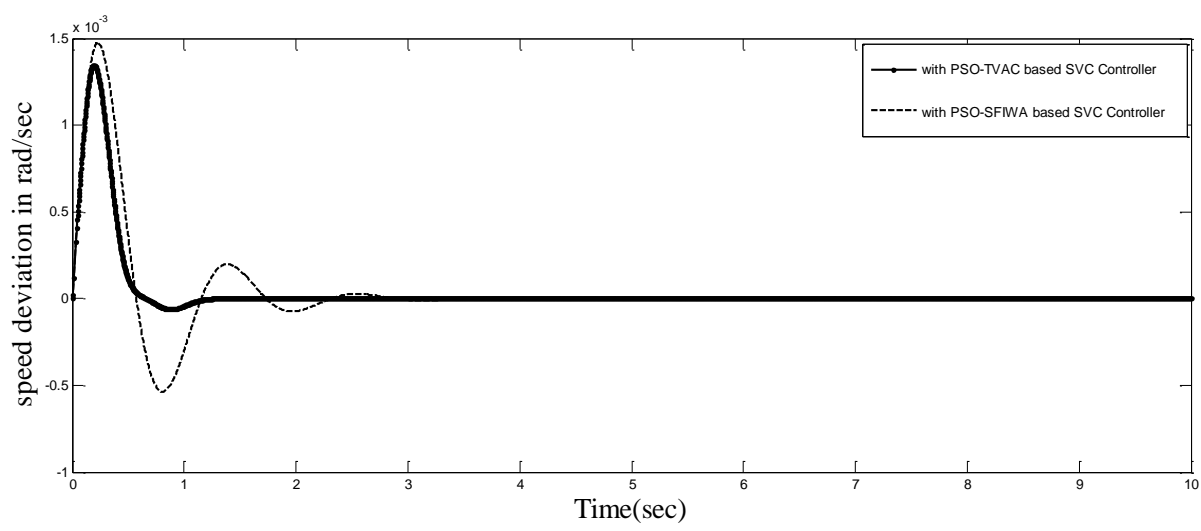

Fig. 9f Time Response of speed deviation 


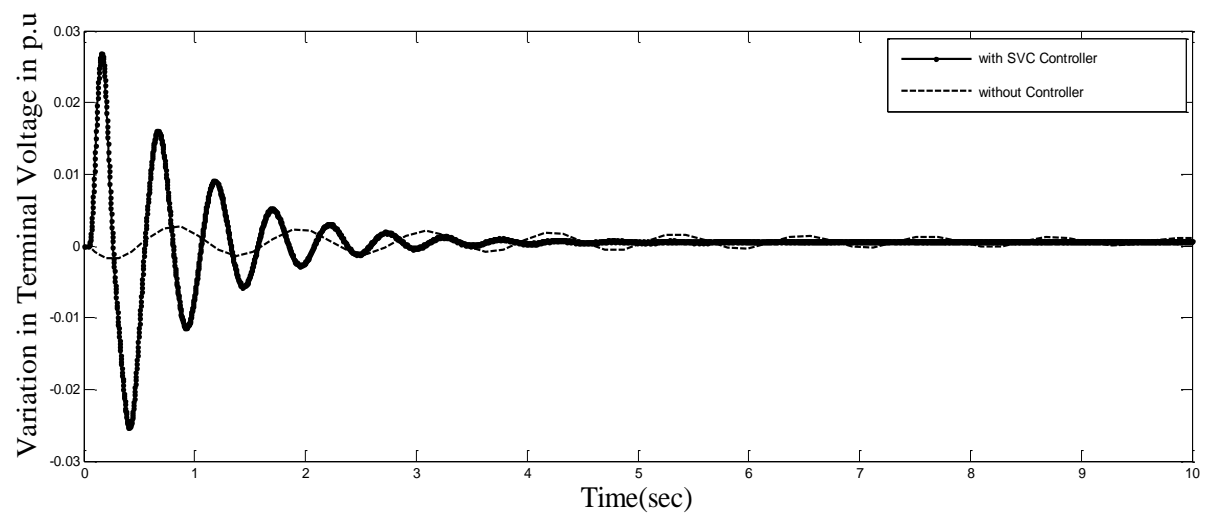

Fig. 9g Time response of variation in terminal voltage

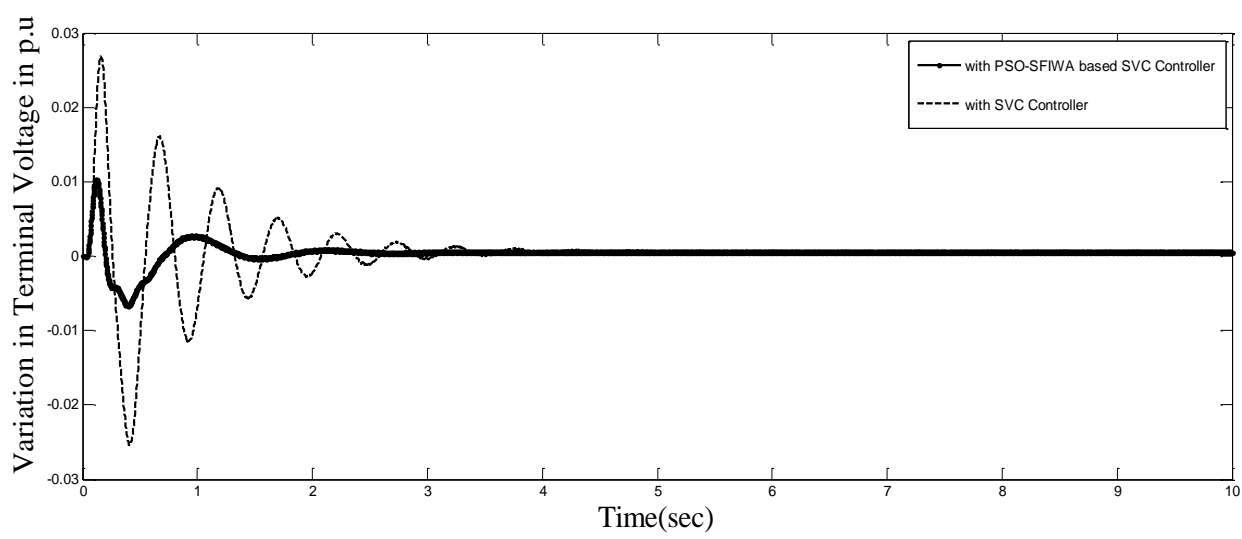

Fig. 9h Time response of variation in terminal voltage

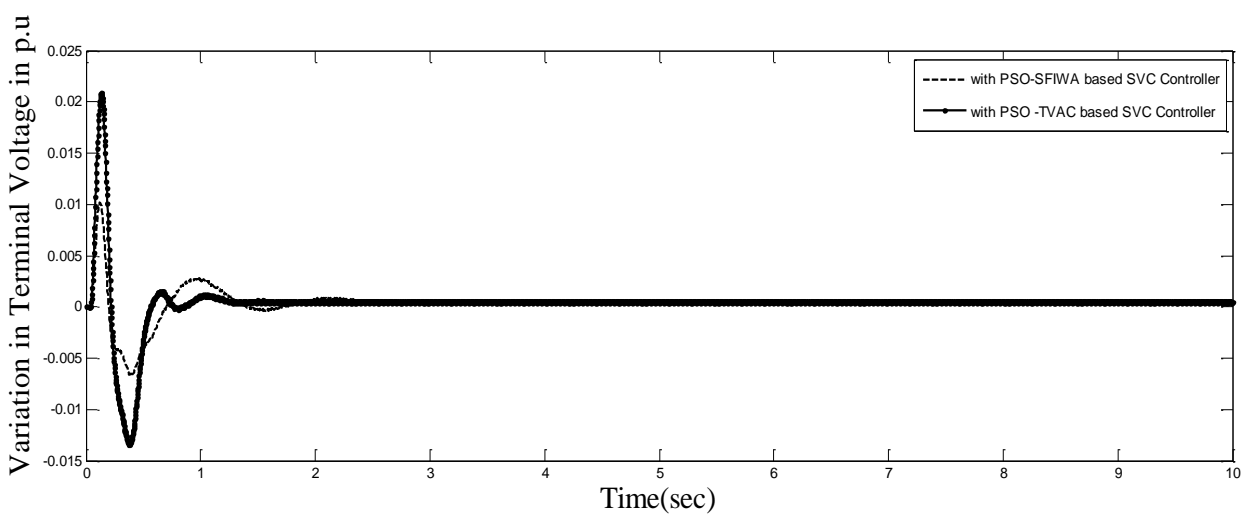

Fig. 9i Time response of variation in terminal voltage

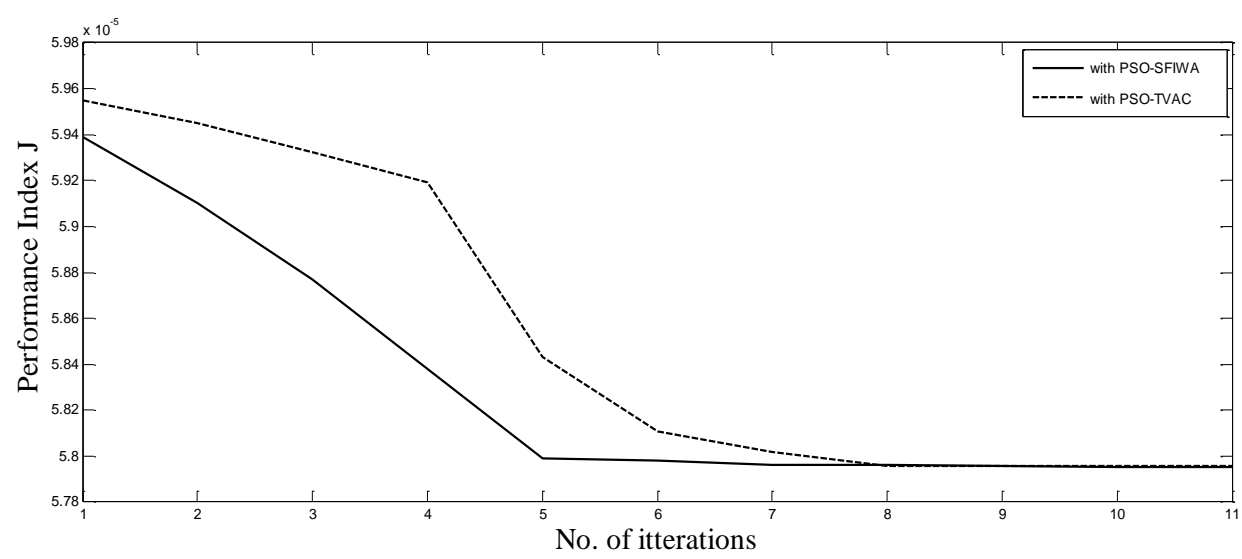

Fig.10 Performance Index curve 
Table 1. Comparison of settling time of oscillations

\begin{tabular}{|c|c|c|c|}
\hline Cases & $\Delta \delta$ & $\Delta \mathrm{w}$ & $\Delta \mathrm{v}_{\mathrm{t}}$ \\
\hline- & $\begin{array}{c}\text { Settling } \\
\text { time }\end{array}$ & $\begin{array}{c}\text { Settling } \\
\text { time }\end{array}$ & $\begin{array}{c}\text { Settling } \\
\text { time }\end{array}$ \\
\hline $\begin{array}{c}\text { Without SVC } \\
\text { Controller }\end{array}$ & $57 \mathrm{sec}$ & $56 \mathrm{sec}$ & $55 \mathrm{sec}$ \\
\hline $\begin{array}{c}\text { With } \\
\text { SVC Controller }\end{array}$ & $5.3 \mathrm{sec}$ & $5.4 \mathrm{sec}$ & $7 \mathrm{sec}$ \\
\hline $\begin{array}{c}\text { Parameters of PID } \\
\text { damped SVC } \\
\text { Controller using } \\
\text { PSO-SFIWA } \\
\text { approach. }\end{array}$ & $4.2 \mathrm{sec}$ & $4 \mathrm{sec}$ & $4 \mathrm{sec}$ \\
\hline $\begin{array}{c}\text { Parameters of PID } \\
\text { damped SVC } \\
\text { Controller using } \\
\text { PSO-TVAC } \\
\text { approach }\end{array}$ & $1.6 \mathrm{sec}$ & $1.7 \mathrm{sec}$ & $1.8 \mathrm{sec}$ \\
\hline
\end{tabular}

\section{CONCLUSION}

AI based PID damped SVC controller is highly effective in improving the dynamic stability of power system i.e. they damp out the rotor mechanical low frequency oscillations effectively Hence, they can be utilized to replace the existing conventional power system stabilizers in future and can be applied for the real-time control of power system. The simulation results show Advanced Adaptive PSO is more effective than basic PSO and PSO-SFIWA. However the system gets stabilized to a new value of machine angle, but stabilizing the rotor angle to a new position is not of much concern. The main concern is to damp out the speed oscillations quickly to enhance the steady state stability of power system.

\section{APPENDIX}

Generator Data:

$\mathrm{x}_{\mathrm{d}}=1.6, \mathrm{x}_{\mathrm{q}}=1.55, \mathrm{x}_{\mathrm{d}}{ }^{\prime}=0.32, \mathrm{~T}_{\mathrm{do}}{ }^{\prime}=6 \mathrm{sec}, \mathrm{H}=5.0, \mathrm{f}=60 \mathrm{~Hz}$, $\mathrm{x}_{\mathrm{e}}=0.4, \mathrm{D}=0$

Expressions for computing Phillips Heffron model constants:

$$
\begin{aligned}
& K 1=\frac{E_{b} E_{q o} \cos \delta_{o}}{\left(x_{e}+x_{q}\right)}+\frac{\left(x_{q}-x_{d}\right)}{\left(x_{e}+x_{d}^{\prime}\right)} E_{b} i_{q o} \sin \delta_{o} \\
& K 2=\frac{x_{e}+x_{q}}{\left(x_{e}+x_{d}^{\prime}\right)} i_{q o}=\frac{E_{b} \sin \delta_{o}}{\left(x_{e}+x_{d}^{\prime}\right)} \\
& K 3=\frac{x_{e}+x_{d}^{\prime}}{x_{d}+x_{e}} \\
& K 4=\left(\frac{x_{d}-x_{d}^{\prime}}{\left(x_{d}^{\prime}+x_{e}\right)}\right) E_{B} \sin \delta_{o} \\
& K 5=\frac{-x_{q} v_{d o} E_{b} \cos \delta_{o}}{\left(x_{e}+x_{q}\right) V_{t o}}-\frac{x_{d}^{\prime} v_{q o} E_{b} \sin \delta_{o}}{\left(x_{e}+x_{d}^{\prime}\right) V_{t o}}
\end{aligned}
$$

$$
K 6=\frac{x_{e}}{\left(x_{e}+x_{d}^{\prime}\right)}\left(\frac{v_{q o}}{V_{t o}}\right)
$$

Exciter data:

$\mathrm{K}_{\mathrm{E}}=200, \mathrm{~T}_{\mathrm{E}}=0.05 \mathrm{sec}$

SVC Controller data:

$\mathrm{K}_{\mathrm{R}}=80, \mathrm{~T}_{\mathrm{R}}=0.025 \mathrm{sec}, \mathrm{T}_{\mathrm{d}}=0.0371 \mathrm{sec}, \mathrm{T}_{\mathrm{b}}=0.0375 \mathrm{sec}$

$\mathrm{Z}_{\mathrm{th}}=0.02$ p.u, $\mathrm{T}_{\mathrm{m}}=0.000795$ seconds

PSO Parameters:

Population $=50, \mathrm{c} 1=2.05, \mathrm{c} 2=2.05$, itermax $=10, \mathrm{c} 1 \mathrm{i}=2.5$, $\mathrm{c} 2 \mathrm{f}=0.5, \mathrm{c} 2 \mathrm{i}=0.5, \mathrm{c} 2 \mathrm{f}=2.5, \mathrm{w}_{\max }=0.9, \mathrm{w}_{\min }=0.4, \mathrm{k}_{\min }=[0.5$ $-0.50 .01], \mathrm{k}_{\max }=\left[\begin{array}{lll}0.7 & -0.3 & 0.02\end{array}\right]$

Table 2. PID controller parameters:

\begin{tabular}{|c|c|c|c|}
\hline CASES & $\mathrm{k}_{\mathrm{p}}$ & $\mathrm{k}_{\mathrm{i}}$ & $\mathrm{k}_{\mathrm{d}}$ \\
\hline $\begin{array}{c}\text { Without SVC } \\
\text { Controller }\end{array}$ & ---- & ---- & ---- \\
\hline $\begin{array}{c}\text { With SVC } \\
\text { Controller }\end{array}$ & ---- & --- & ---- \\
\hline $\begin{array}{c}\text { Parameters of PID } \\
\text { damped SVC } \\
\text { Controller using } \\
\text { PSO-SFIWA } \\
\text { approach. }\end{array}$ & 0.3171 & -.459 & .0147 \\
\hline $\begin{array}{c}\text { Parameters of PID } \\
\text { damped SVC } \\
\text { Controller using } \\
\text { PSO-TVAC } \\
\text { approach }\end{array}$ & 0.6969 & -0.5 & 0.02 \\
\hline
\end{tabular}

\section{REFERENCES}

[1] N. G. Hingorani, L. Gyugyi, "Understanding FACTS", IEEE Press, 2001.

[2] P. Kundur, "Power System Stability and Control", Tata McGraw-Hill, 2006.

[3] K. R. Padiyar, Power System Dynamics Stability and Control, BS Publications, 2nd Edition, Hyderabad, India, 2002

[4] Y. H. Song, A. T. Johns, "Flexible AC Transmission Systems (FACTS)", IET, 2009

[5] Poonam Singhal, S.K.Aggarwal and Narender Kumar, 'Transient Stability Enhancement using UPFC.'IREMOS, 2013.

[6] Poonam Singhal, S.K.Agarwal, Narender Kumar \& Monika,"Stability Enhancement of a multi-machine power system using Static Var Compensator'IJAIR, volume 2, issue 2,February 2013

[7] Y. Mishra,S. Mishra and Fangxing Li 'Coordinated Tuning of DFIG-Based Wind Turbines and Batteries Using Bacteria Foraging Technique for Maintaining Constant Grid Power Output'. Published in Systems Journal, Volume:6 , Issue: 1,pp.no.16-26, 2012 IEEE

[8] Shengli Song Li Kong and Jingjing Cheng,"A Novel Particle Swarm Optimization model with Centroid and its application" I.J. Intelligent Systems and Applications, 2009, 1, pp.no. 42-49

[9] X.Wang, X. Z. Gao and S. J. Ovaska'.”A Hybrid Particle Swarm Optimization Method", IEEE International Conference on Systems, Man, and Cybernetics, Taipei, Taiwan, October 2006 
[10] Mohamed Zellagui and Abdelaziz Chaghi,'Impact of TCSC on Distance Protection Setting based Modified Particle Swarm Optimization Techniques". I.J. Intelligent Systems and applications 2013,06, pp.no.12-24.

[11] P. S. Shelokar, V. K. Jayaraman, and B. D. Kulkarni,'An ant colony approach for clustering,' Analytica Chimica Acta Vol. 509(2): pp.187-195, 2004

[12] Shah-Hosseini, H. (2009) 'The intelligent water drops algorithm: a nature-inspired swarm-based optimisation algorithm', Int. J.Bio-Inspired Computation, Vol. 1, Nos. $1 / 2$, pp.71-79.

[13] Wang Meihong, Zeng Wenhua*, Wu Keqing. Grid task scheduling based on advanced no velocity PSO'.

[14] Herby Dallard and Sarah S. Lam 'Solving the Orienteering Problem Using Attractive and Repulsive Particle Swarm Optimization', Proceedings in IEEE International Conference on Information Reuse and Integration, IRI 2007, pp. no. 13-15, Las Vegas, Nevada, USA. Heuristic Optimization and Search

[15] Rehab F. Abdel Kader," Genetically Improved PSO Algorithm for Efficient Data Clustering", Second International Conference on Machine Learning and Computing ( icmlc), pp.71-75, 2010.

[16] Wael M. Korani, Hassen Taher Dorrah, Hassan M.Emara,"Bacterial Foraging Oriented by Particle Swarm Optimization strategy for PID Tuning".

[17] Jiao Wei, Liu Guang-bin," An improved Particle Swarm Optimization Algorithm with Immunity". Published in Intelligent Computation Technology and Automation, 2009. ICICTA '09. Second International Conference on 10-11 Oct. 2009.

[18] Hardiansyah, Junaidi, Yohannes Load Dispatch using Bacterial Foraging Technique with Particle Swarm Optimization Biased Evolution”. I.J. Intelligent Systems and applications 2012,12 , pp. 12-18

[19] JinJin-Zhu Hu,Jia-qiao Wang, Ting Xu," Research on Particle Swarm Optimization with dynamic inertia weight'. Published in 2010 International Conference on Computer Design and Applications (ICCDA 2010).

[20] D.Harikrishna, N.V.Srikanth,'Unified Phillips-Heffron Model of Multi Machine Power System equipped with PID Damping Controlled SVC for Power Oscillation Damping." Published in India Conference (INDICON), 2009 Annual IEEE, 18-20 Dec. 2009

[21] J. Kennedy and R. Eberhart, "Particle swarm optimization," in Proc .IEEE Int. Conf. Neural Networks, 1995, pp. 1942-1948.

[22] Y.Shi and Russel Eberhart," Comparing Inertia Weights and Constriction Factors in Particle Swarm Optimization". Published in: Evolutionary Computation, Proceedings of the 2001

[23] IEEE special stability controls working group, Static VAR compensator models for power flow and Dynamic performance simulation. IEEE Transaction on power systems, Vol. 19, No. 1, February 1994, pp. 229 - 239.

[24] Clerc, "The swarm and the queen: Toward a deterministic and adaptive particle swarm optimization," in Proc. IEEE Int. Congr .Evolutionary Computation, vol. 3, 1999, p. 1957.

[25] M. Clerc and J.Kennedy, "The particle swarm-Explosion, stability, and convergence in a multi-dimensional complex space," IEEE Trans. Evol .Comput., vol. 6, pp. 58-73, Feb. 2002.

[26] Asanga Ratanvweera, Saman K. Halgamuge,Harry C.watson, "Self Organising Hierarchical Particle Swarm Optimizater with Time-Varying Acceleration
Coefficient."IEEE Transaction on Evolutionary Computation, 2004

[27] Rajendraprasad Narne and Prafulla Chandra Panda,"Coordinated Design PSS of withMultiple FACTS Controllers using Advanced Adaptive PSO". International Journal on Electrical Engineering and Informatics Volume 5,Number 3, September 2013

\section{Author's Profile}

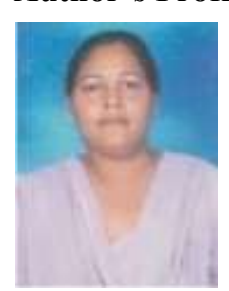

Poonam Singhal was born in 1964. She is currently Associate Professor in YMCA University of Science \& Technology, Faridabad; Haryana (India).She did her B.Sc Engg from REC Rourkela, Odhisa (India) \&M.Tech (Power System \& Drives) from YMCA University of Science \& Technology, Faridabad, Haryana (India). Her main area of interest is FACTS, Power System Operation control \& Simulation.

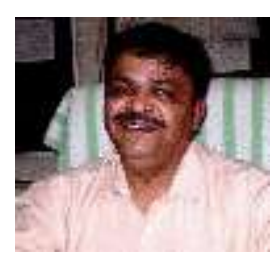

S. K Agarwal was born in 1961 . He is currently Professor in Department of Electronics Engineering; YMCA University of Science \& Technology, Faridabad, and Haryana (India) .He did his B.Tech from REC Calicut, Kerela (India) \& M.E. (Controls \& Instrumentation) from Delhi Technological University Delhi (India) \&Ph.D from JamiaMiliaIslamia University Delhi (India).

Prof. S. K. Agarwal has many publications in National/International Journals \& presented papers in International conferences. Prof. Agarwal's main area of interest is Power System \& Controls.

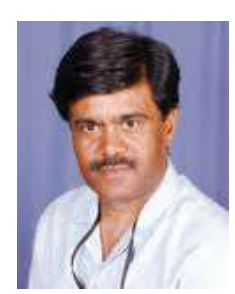

Narender Kumar was born in Aligarh (India). He received his B.Sc. Engg. \& M.Sc. Engg in Electrical Engineering from A.M.U. Aligarh in 1984 \& 1986 respectively. Presently, he is Professor of Electrical Engg. in Delhi Technological University, Delhi.

Prof. Narender Kumar has published various papers in national and international conferences and journals. Prof. NarenderKumar's main area of interest are Power System Operation Control \& Simulation, SSR, AGC etc.

How to cite this paper: Poonam Singhal, S. K. Agarwal, Narendra Kumar,"Advanced Adaptive Particle Swarm Optimization based SVC Controller for Power System Stability", IJISA, vol.7, no.1, pp.101-110, 2015. DOI: 10.5815/ijisa.2015.01.10 